\title{
INTERAÇÕES FOTOETNOGRÁFICAS: O "EU" E O "OUTRO" NA PRAÇA DE FÁTIMA - ITZ
}

\author{
Jesus Marmanillo ${ }^{1}$
}

\section{Introdução}

\begin{abstract}
É possível que suspeite terem os etnógrafos se unido numa conspiração de silêncio sobre esses problemas. quanto ele, por sua vez, se tornar um autêntico etnógrafo poderá engajar-se inadvertidamente nessa conspiração, ou sentir-se obrigado a fazêlo, não só para proteger os segredos da etnografia, como para proteger-se. Devido às regras do jogo, que impediram os outros de lhe comunicarem suas experiências, é possível que considere suas próprias dificuldades de ânimo e de relacionamento, seus próprios compromissos entre o ideal e o necessário como sendo singulares e, talvez, como sinais de fraqueza ou de incompetência. (Berreman, 1975: 123).
\end{abstract}

Como observa Berreman (1975) os etnólogos raramente explicitam os meios pelos quais a informação foi colhida, e nem expõem os aspectos do campo que extravazam uma definição convencional de método. Seguindo em sentido oposto, o presente artigo visa demonstrar a importância da problematização da interação entre etnógrafo e nativos, ou seja, discorreremos sobre a relação entre fotoetnografia ${ }^{2}$, relações em locais públicos e condições da pesquisa, tomando como parâmetro os primeiros contatos em campo e o problema epistemológico da relação sujeito-objeto.

Para tanto tomamos como referência a experiência de trabalho no projeto de extensão "Praças do tempo: Cotidiano, Imagens e memórias do centro urbano de Imperatriz". Por meio desse, iniciei as primeiras inserções na Praça de Fátima, durante o mês de setembro de 2014, realizando observações diretas e registros fotográficos a fim de construir uma narrativa visual que apontasse às dinâmicas interacionais que davam cor e forma a referida Praça.

Problematizando tal experiência, no âmbito das relações etnógrafo - sujeitos e etnógrafo - etnógrafo, percebi uma rica possibilidade de reflexão sobre um constante aspecto interacionista que ronda o fazer antropológico seja no trabalho de campo, ou quando tomamos nossos pares como nativos. Seguindo esse viés, se refletiu sobre a perspectiva polarizada que considera o contato entre pesquisador como determinado na

\footnotetext{
${ }^{1}$ Universidade Federal do Maranhão, Brasil.

${ }^{2}$ Entendemos Fotoetnografia na acepção de Achutti (2004, 2004a), valorizando uma combinação entre o olhar treinado do antropólogo e a linguagem fotográfica.
} 
relação entre o "eu" e o "outro", buscando demonstrar que entre esses dois pontos há um tipo de degradação que nos possibilita pensar várias possibilidades de inserção do "eu" que repercuti em diferentes formas de inserção e contato.

Um passo importante nesse sentido já foi dado por Cardoso de Oliveira (2006) quando enfatizou a importância de compreender a identidade propriamente dita e o "eu" (ego, self) entendido como agência estratégica de articulação de identidades sociais diante do mundo moral. Mundo esse, considerado pelo autor como pano de fundo no qual o "eu" desenvolve sua liberdade de escolha das identidades postas à sua disposição no interior de um sistema cultural concreto.

Inserindo-se nessa agenda de pesquisas e reflexões, o presente artigo está dividindo em duas partes, sendo trabalhada, primeiramente, uma breve relação entre o método fotoetnográfico e possíveis diálogos com a sociologia de Erving Goffman, e posteriormente um relato de minhas primeiras inserções em campo, elencando elementos como: cenário, atores, interações em relação às condições de produção dos registros etnográficos e fotoetnogáficos.

\title{
Eu, o outro e a interação: diálogos entre Antropologia a micro sociologia
}

\begin{abstract}
Ao chegar em campo, todo etnógrafo se vê imediatamente confrontado com sua própria apresentação diante do grupo, que pretende aprender a conhecer. Só depois de tê-lo feito, poderá passar à sua confessada tarefa de procurar compreender e interpretar o modo de vida dessas pessoas. Na literatura antropológica, a segunda dessas tarefas é mais frequentemente discutida que a primeira. Conquanto o êxito do esforço dependa tanto de uma quanto da outra. Ambas as tarefas, como toda interação social, envolvem controle de interpretação pelo etnógrafo e seus sujeitos. (Berreman, 1975: 125).
\end{abstract}

Em se tratando de método, a etnografia ocupa um lugar central na Antropologia, podendo ser observada em um conjunto de debates e reflexões ao longo do pensamento antropológico. Para Malinowksi (1975) a primeira meta do trabalho etnográfico é fornecer um esquema claro e firme da constituição social, bem como destacar as leis e normas de todos os fenômenos culturais, buscando apreender as normas e regras da vida tribal. Detalhando um pouco mais, Strauss (2003) explica a etnografia, provisoriamente, como a observação e análise de grupos humanos considerados em suas particularidades visando à reconstituição tão fiel quanto possível da vida de cada um deles. Já Geertz (2005) explica que o papel do etnógrafo consiste em ir a determinados lugares e voltar de lá com informações de seu objeto, visando disponibilizá-las com a comunidade 
especializada. Reforçando e complementando todas essas explicações, Clifford (2008) ressalta que a operação fundamental da pesquisa etnográfica é traduzir a experiência de campo em um corpus textual conhecido como etnográfico.

Como observa Berreman (1975) na literatura antropológica são numerosos os trabalhos que discorrem e explicam esse método pelo qual o etnógrafo busca compreender e interpretar a vida dos nativos. No entanto, a questão da confrontação do etnógrafo com sua própria apresentação diante do grupo estudado é um ponto menos frequente no debate acadêmico. É por meio desse segundo aspecto que é possível discorrer sobre os obstáculos, desânimos, asperezas do trabalho de campo, e também refletir sobre o próprio posicionamento do pesquisador e seu habitus antropológico.

Valorizar esse ponto destacado por Berreman (1975) significa, entre outras coisas, analisar o processo de interação entre pesquisador e objeto, ou seja, não se conformar apenas com a disposição antagônica entre o "eu" e o "outro", mas pensá-los de acordo com o próprio processo de interação social, denotando assim, a problematização acerca do próprio papel do pesquisador, e por outro lado, inserindo uma micro analise sociológica de viés Goffmaniano no fazer etnográfico. É importante destacar que a questão da interação entre sujeito e objeto não constitui uma novidade, sendo trabalhada inclusive por autores como, por exemplo, DaMatta (1978) discorre que a inserção no campo é permeada pela relação entre pesquisador e nativo, da qual emergem aspectos extraordinários que nos fazem entender que é necessário saber conciliar os manuais e rotinas de campo com as situações não previstas permeadas por emoções e outros valores desenvolvidos na relação etnógrafo- nativo. Outro autor de destaque nacional é Cardoso de Oliveira $(1976,2006)$ que nos possibilita pensar a relação entre o "eu" e o "outro" pelo aspecto da identidade, seguindo assim, uma perspectiva relacional que considera a manipulação do "eu”, as situações e tipos de contato.

Outro autor que também pode ser destacado é Bourdieu (2007) quando problematiza uma interação entre o pesquisador e o entrevistado. Para tanto, ele argumenta que por mais que a pesquisa científica se diferencie das experiências comuns, ela constitui, antes de tudo, uma relação social. Nesse sentido, explica que é necessário pensar: os efeitos da entrevista, os estímulos dados e provocados e a forma como os entrevistados se relacionam com a situação. Sobre esse processo de entrevista ele percebe que: 
É o pesquisador que inicia o jogo e estabelece a regra do jogo, é ele quem geralmente, atribuí à entrevista, de maneira unilateral e sem negociação prévia, os objetivos e hábitos, às vezes mal determinados, ao menos para o pesquisado. Esta dissimetria é redobrada por uma dissimetria social todas as vezes que o pesquisador ocupa uma posição superior ao pesquisado na hierarquia das diferentes espécies de capital, especialmente capital cultural. O mercado dos bens linguísticos e simbólicos que se institui por ocasião a entrevista varia em sua estrutura segundo a relação objetiva entre o pesquisador e o pesquisado ou, o que dá no mesmo, entre todos os tipos de capitais, em particular os linguísticos, dos quais estão dotados. (Bourdieu, 2007: 695)

Uma contribuição importante desse autor é considerar a situação, estímulos e interação entre pesquisador e pesquisado, considerando-a antes de tudo como uma relação social cujos envolvidos também são alvo de análises. Tal relação é analisada detalhadamente no artigo "Etnografia e controle de impressões em uma aldeia do Himalaia" escrito por Gerald Berreman, sob forte influência do interacionismo simbólico de Erving Goffman.

Tal como Malinowiski, esse autor inicia sua narrativa expondo a distância e algumas dificuldades de inserção em uma aldeia cuja sociedade é estreitamente fechada e rigidamente estratificada, contudo dá atenção especial aos diferentes efeitos nos processos de identificação do etnógrafo com os grupos de alto e baixo status, na comunidade, valorizando assim as situações de interação e principalmente o controle de impressões desenvolvidos durante tais processos. Segundo ele:

O controle de impressões constitui um aspecto de qualquer interação social. Trata-se aparentemente, de uma condição necessária à continuidade da interação social. Para uma pesquisa etnográfica competente, é essencial compreender a natureza e os desempenhos resultantes. Devem ser empregados procedimentos metodológicos que revelem não só o desempenho montado para o observador, mas também a natureza dos esforços empregados na sua produção e a situação dos bastidores que oculta. (Berreman, 1975: 174).

Para compreender melhor essa relação entre controle de impressões s situações de interação social, o autor explica que tais impressões são promovidas a partir de uma região interna, dos indivíduos, e expostas em uma região exterior onde é observada por uma plateia. Dessa forma, problematiza as primeiras impressões e informações mais evidentes, afirmando a necessidade do etnógrafo não se deter em apenas as opiniões e 
comportamentos de um estrato, mas na relação entre os diversos estratos com seus respectivos comportamentos e informações.

Nessa linha o autor expõe as condições da pesquisa, um mapeamento da composição social da aldeia e interações com os nativos, explicando a entrada no local por meio do contato com um atacadista que comprava o excedente da produção da aldeia e, as implicações de sua associação com o mesmo, já que o comerciante possuía significados específicos para os aldeões. Em sua etnografia, explica às vezes que foi confundido com missionário, a desconfiança dos aldeões e o momento em que passou a adquirir confiança dos nativos. Enfim, para o autor o etnógrafo inserido em uma sociedade rígida e estratificada, nunca deixará de ser um estranho. Será sempre avaliado por aqueles entre os quais trabalha, por suas características, pelas características de seus associados e identificado com grupos ou sujeitos com o quais possui acesso.

Enfim, para analisar a própria apresentação diante do grupo que pretende aprender, uma rica possibilidade é o estudo das ações e impressões que compõem os processos de interação e identificação dos signos (símbolos) capazes de transmitir informações sociais (Goffman, 1988). Nesse sentido, mais que pensar o "eu" e o "outro" de forma estática, os textos a seguir, buscaram demonstrar a dinâmica interacional existente, tomando como recorte uma experiência de campo realizada na Praça de Fátima, na cidade de Imperatriz-MA.

\section{Cenário, atores e interações}

A Praça de Fátima pode ser compreendida como um espaço central que caracteriza muito a memória e o cotidiano do cidadão imperatrizense, principalmente daqueles consumidores do centro comercial e administrativo da cidade. Tanto o nome da Praça, quando o fato de uma de suas laterais ser ocupada, quase inteiramente, pela igreja Nossa Senhora da Fátima, nos possibilita pensar na existência de uma relação entre a Praça e a Igreja, cuja construção foi iniciada em agosto de 1954. Segundo a enciclopédia de Imperatriz (2012) a Praça é um logradouro público localizado em frente a Paróquia Nossa senhora de Fátima, Catedral da Diocese de Imperatriz, no Centro da cidade e possui área de $3.101,29 \mathrm{~m}^{2}$.

Observando a Praça de Fátima por uma imagem de satélite (Ilustração 1) e pela fotografia será possível visualizar a igreja de Fátima com uma área limpa na frente 
cercada por árvores que delimitam o lado oposto e a lateral direita da igreja. Já o outro lado da área retangular tem-se árvores de menor porte, duas lanchonetes e um estacionamento de carros. Por meio do trabalho de campo, notamos que por baixo dessas árvores ocorre um verdadeiro sistema de interação composto por uma série de atores sociais que serão tratados com mais detalhes, no decorrer do texto.

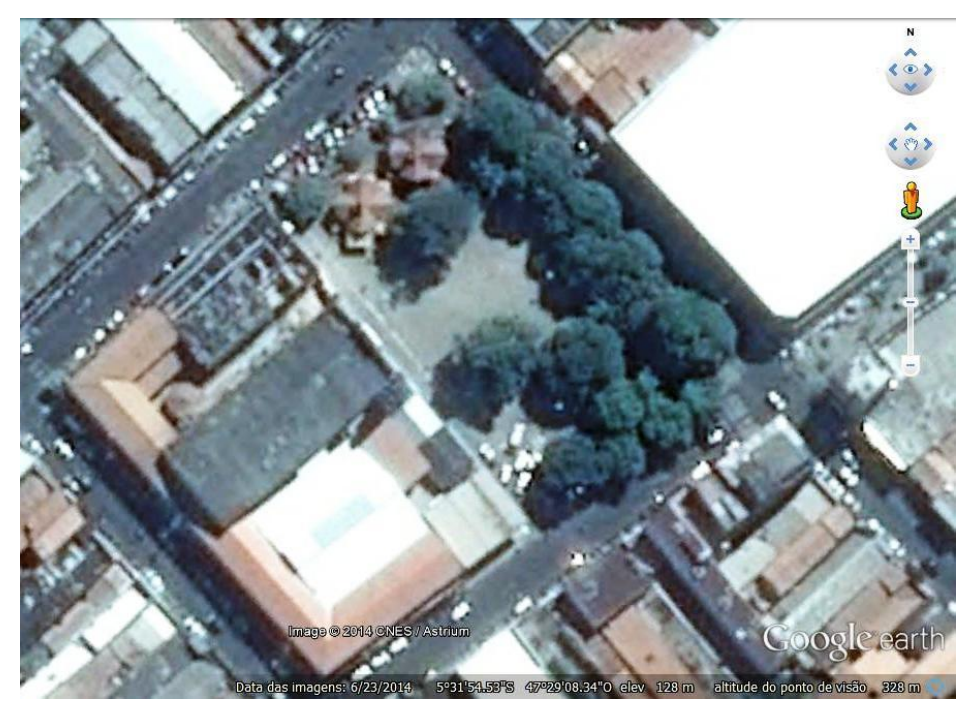

Ilustração 1- Imagem de Satélite da Praça de Fátima Fonte: Googleearth, 2014.

A forma de ocupação da Praça pode ser interpretada de uma forma mais estrutural pensada em relação ao centro comercial e também por conta das condições físicas de permanência no espaço, associadas à existência a um conjunto de atores sociais compostos por: taxistas, flanelinhas, idosos, comerciantes e pedestres em trânsito, que grosso modo, podem ser sistematizados em dois grupos: os que permanecem cotidianamente na Praça e os que a vivem apenas como local de passagem.

Nesse sentido, é possível observar que pelo menos três tipos aparecem nas Ilustrações 2 e 3 (a seguir), que de forma mais geral expõe algumas características ambientais e a ocupação do espaço dado por três tipos de atores sociais: uma flanelinha sentada em frente a uma fileira de carros privados, um grupo de taxistas próximos a uma fileira de taxis e um transuente, no fundo da imagem. 


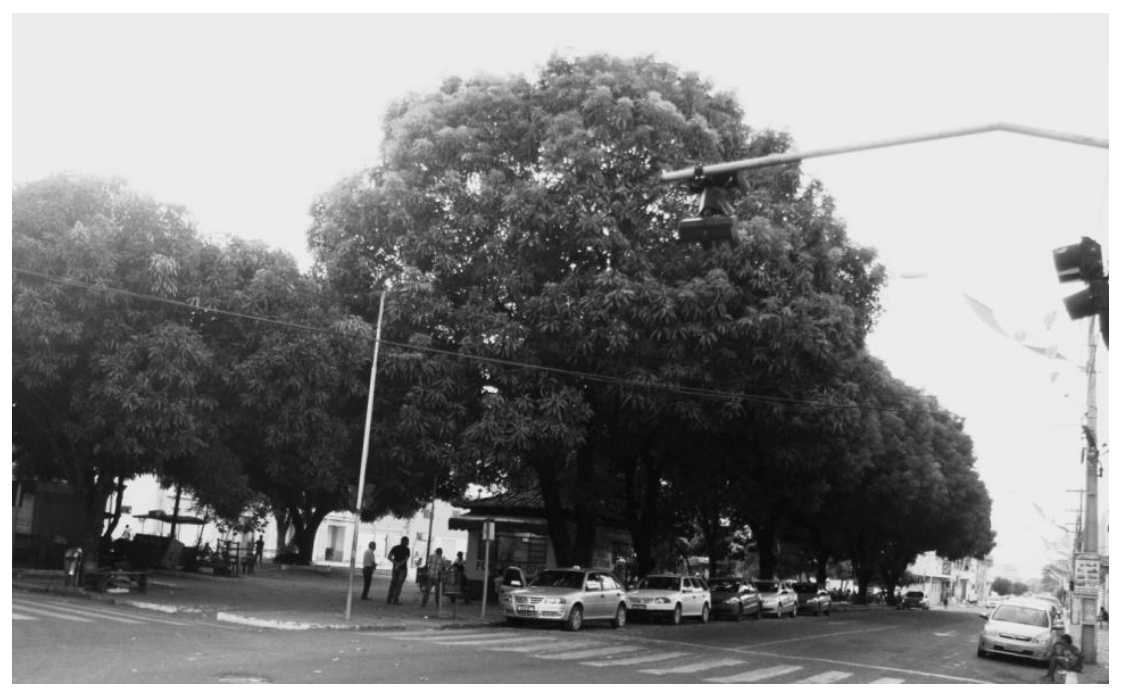

Ilustração 2 - Grupos de taxistas e flanelinha sentada no outro lado da calçada. Foto: Marmanillo, 2014.

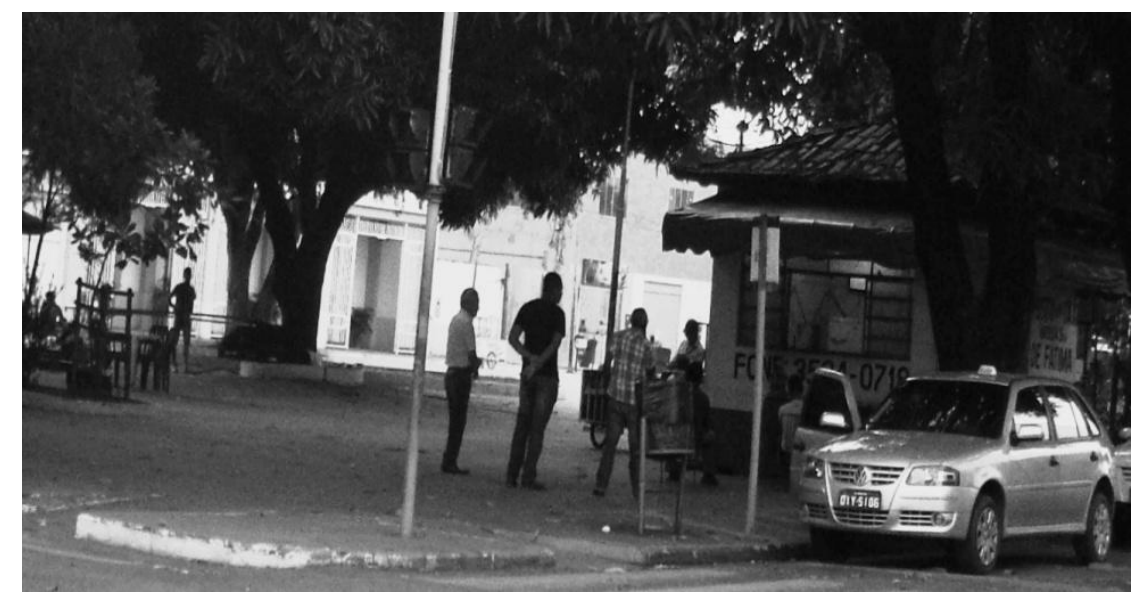

Ilustração 3 - Transuente e taxistas.

Foto: Marmanillo, 2014.

É importante ressaltar que a localização dos taxistas, banca de revistas e maior concentração de assentos são mais próximas ao calçadão comercial da Avenida Getúlio Vargas, cujo início ocorre no lado oposto a uma das esquinas da Praça de Fátima. Em relação à dinâmica interna da Praça, observamos que as árvores servem como verdadeiros abrigos que produzem sombra e conforto diante as elevadas temperaturas de Imperatriz, que chegam a alcançar $36^{\circ}$. Assim, os atores fixos que trabalham na Praça concentram-se cotidianamente nessas áreas, enquanto os pedestres podem ser observados quando trafegam pela parte central da Praça que é mais limpa, ou quando se 
deslocam entre os trabalhadores que vivem o cotidiano local ou pessoas que sentam por algum tempo para descansar ou dialogar com amigos sobre as sombras das árvores.

Buscando detalhar esses tipos de atores urbanos Frehse (2013) utiliza os termos transeuntes e não transeuntes, os primeiros caracterizados pela permanência regular em determinadas vias e logradouros. Trata-se de uma classificação que se referencia no comportamento corporal dos atores cujo foco analítico é baseado em uma perspectiva relacional o entre essas duas formas de atores e interacional no contato entre pesquisador e objeto.

Segundo a autora, a perspectiva Goffmaniana a interação social envolve a comunicação simbólica entre os atos de atores que estejam em copresença física em determinados ambientes espaciais. Nesse sentido é importante problematiza a própria condição social da produção das fotografias, que pode ser pensada em duas etapas: As primeiras foram realizadas sem permissão e com certo distanciamento. Visavam captar enquadramentos mais amplos, contextuais e coletivos - sem o foco em sujeitos específicos. Tal forma de fotografia foi associada aos meus primeiros contextos de inserção em campo- sem muito conhecimento local- que exigiam uma facilidade de registrar e obter mais informações que facilitassem futuros contatos e fotografias mais detalhadas sobre atores específicos.

Sobre minha própria relação com os nativos, as Ilustrações 2 e 3 trazem uma informação valiosa que evidencia a própria etapa da pesquisa, ou seja, o distanciamento em relação ao objeto fotoetnografado. As imagens foram registradas com uma distância de cerca de 30 metros em uma área comercial do outro lado da rua que dá acesso a Praça. Tratam-se dos primeiros contatos, da coleta das informações mais gerais, sem detalhamento nem identificação de atores específicos. Pode-se dizer que essa fase foi marcada fortemente por uma espécie de voyerismo marcado pelo desejo de observar e registrar de forma distanciada, e sem interação direta com os nativos. Como é possível observar nas imagens, o máximo de aproximação deu-se via o recurso de zoom do equipamento fotográfico.

É importante explicar que meu receio de uma aproximação imediata foi decorrente de minha própria condição de novo morador na cidade, ou seja, residente desde julho de 2014. Tentando tirar proveito dessa condição de estranhamento, desenvolvi caminhadas cotidianas, coletando informações sobre as pessoas, história e costumes do centro urbano imperatrizense, dados que serviram para a elaboração do 
projeto "Praças do tempo: Cotidiano, Imagens e memórias do centro urbano de Imperatriz" aprovado e financiado pela Pró-Reitoria de extensão da Universidade Federal do Maranhão. Ao mesmo tempo que, a condição de "novato" me possibilitou o estranhamento de coisas que cotidianamente eram naturalizadas, por outro lado, representou também o papel do forasteiro, do estranho, que trouxe algumas dificuldades de contato mais direto com alguns frequentadores e trabalhadores da Praça de Fátima.

Durante cinco meses de visitas sistemáticas e informais na Praça de Fátima, percebi concretamente o que Berreman (1975) desejou expressar quando afirmou que o etnógrafo é sempre inevitavelmente um estranho e nunca vai deixar de sê-lo. Nesse sentido recordo de três ou quatro vezes ser classificado como gringo, por taxistas, comerciantes ou colegas de trabalho da própria universidade. Em cima dessas classificações busquei me associar a elementos locais, a própria posição de trabalho, de consumidor de serviços e de usuário de bicicleta, veículo mais popular na cidade.

Analisadas as vantagens e desvantagens do papel social que me era atribuído naquela situação, me restava considerar todas essas informações sociais e tentar buscar alguma forma de aproximação com os nativos. A primeira tentativa sistematizada de contato direto ocorreu em 30 de outubro de 2014, dia em que cheguei de bicicleta na banca de revista da Praça e pedi uma água mineral para o vendedor conhecido como Chico.

Sobre esse local específico é importante explicar que a área no entorno da banca sempre além de próxima ao ponto de taxi é munida de cadeiras domésticas onde as pessoas conversam ou lá permanecem a espera de alguém. Esse espaço de concentração é conhecido como "boca maldita", segundo moradores próximos, pois se trata de um local onde são debatidos assuntos da política da cidade e também desenvolvidas fofocas sobre a vida alheia. Segundo a reportagem intitulada "A mesma praça, o mesmo banco e diferentes "papos"”:

Lá não tem balanço, gangorra e raramente se vê crianças correndo. Mas é na mesma praça, no mesmo banco que há 20 anos as pessoas se reúnem diariamente. É ao lado da banca de revista da Praça de Fátima que elas conversam sobre os principais acontecimentos da cidade.

O lugar começou a ser tão visitado que passou a ser conhecido como Boca Maldita. E personalidades importantes de Imperatriz passam por lá: o ex-vereador e escritorEdmilson Sanches, o editor do Jornal O Progresso - Coriolano Filho e a lista segue, extensa.

"Começou naturalmente. As pessoas começaram a vir para cá, comprar jornal ou revista e debater", lembra o dono da banca de revista da Praça, Francisco Melo Santos - o Chico da Banca. 
Gari, jornalista, políticos, médico ou advogado. O público que frequenta a "Boca Maldita" é diversificado e os assuntos também. Segundo o Chico da Banca, é discutido política, economia, cultura e até os bastidores da vida de pessoas públicas (ou não) entram em pauta. ${ }^{3}$

Diante de todas essas características e achando ser um ponto interessante de observação, me dirigir para a referida banca na manhã do dia 30 de outubro. O primeiro contato desenvolveu-se de forma objetiva em um simples diálogo composto de três frases relacionadas ao preço da água, a informação do preço fornecida por ele e a solicitação do produto, por mim.

A expressão facial e corporal economizada ao extremo deram sinais de que o mais sensato seria classificar aquele contexto como uma simples situação entre comerciante e consumidor. Tal característica, do vendedor da banca, pode ser verificada também nas fotografias da reportagem intitulada "A mesma praça, o mesmo banco e diferentes 'papos' que apesar de ter como ator central o "Chico da Banca" as imagens registram a banca sem o Chico, ou seja, indica um processo de interação entre ator e repórter, no qual a não exposição do primeiro prevaleceu, como é possível verificar na Ilustração 4.

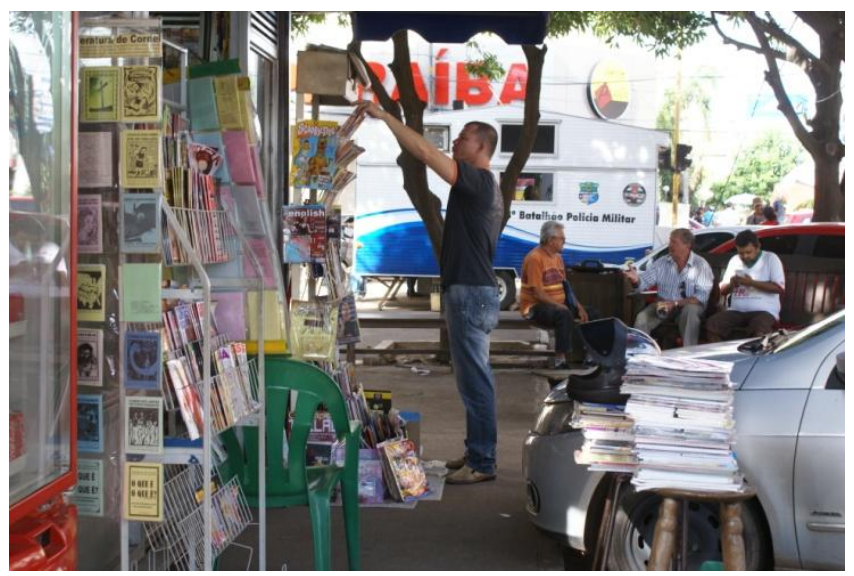

Ilustração 4- Pauta "sem" ator.

Fonte: http://www.portalativo.com.br/portal/noticia/id/170 
Enfim, tentando demonstrar naturalidade, sai da banca e bebi a água de forma tranquila em local próximo, onde me pus a tirar algumas fotos do local como se fosse um turista- crendo que no mínimo o interesse comercial poderia me possibilitar o contato com mais alguém daquele local. Uma segunda tentativa de contato foi com um senhor que chegou à banca e folheava uma revista que trazia um destaque para a vitória da Dilma Rousseff na campanha presidencial. Na situação comentei que a vitória dela foi apertada, e o senhor se posicionou criticando os políticos de forma geral. Quando perguntei se ele era de Imperatriz mesmo, o mesmo respondeu de forma curta e hostil: Não, eu não moro aqui. Não deixando possibilidade alguma de continuidade da interação.

Ambas as situações que, a primeira vista, podem sinaliza um tipo de surpresa, obstáculo ou situação embaraçosa, sinalizam também uma informação social sobre o cotidiano local. Sobre isso Martins (2008) explica que a sociologia de Goffman valoriza a existência das emoções nos processos interacionais, principalmente nas situações que criam sentimentos de desconforto, ansiedade, medo, vergonha e humilhação para os atores envolvidos nesse processo. Para este autor, o embaraço relacionado à sensação de desconforto, oriunda de uma interação, possui importância social porque liga os nervos da organização social ao dia a dia, em outros termos, está associado aos atores e também aos valores e conversões existentes na organização social dos mesmos.

Se pensada em relação à experiência compartilhada por Berreman (1975) quando busca inserção em uma sociedade rigidamente estratificada, posso dizer que minha presença não foi reconhecida como inserida na organização social presente naquele cenário. Não sendo uma cidade reconhecida pelo turismo os forasteiros podem ser mais facilmente associados a pistoleiros, atores que fizeram o nome da cidade ganhar destaque nacionalmente e na imprensa do Estado, durante a década de 1980 (Fregona, 1998). Sobre o ambiente de medo e violência, observamos trechos de reportagens como esse a seguir:

Estar em Imperatriz é não saber se amanhã vai começar o dia vivo. A qualquer momento, o cidadão imperatrizense, por mais pacato que seja poderá ser varado por uma bala deferida pelos pistoleiros que aqui atuam impunemente (O Estado do Maranhão, 18/04/1986: 11) ${ }^{4}$.

\footnotetext{
${ }^{4}$ Reportagem intitulada: Impunidade de Crimes atemoriza população.
} 
Se considerarmos essa imagem construída em torno da violência em Imperatriz em relação ao comportamento desconfiado e hostil registrado em meus primeiros contatos é possível inferir que minha apresentação com características exógenas ao local, não só reafirmou a posição de forasteiro como, provavelmente, reforçou uma necessidade dos locais de manter cautela frente a um desconhecido que pode ser pensado como possível agressor.

Se o conhecimento das informações sociais dos atores é algo importante para o desenvolvimento das interações (Goffman, 2013), em uma sociedade marcada pela violência, tais informações possuem um valor ainda maior para que haja comunicação e interação. Dessa forma, minhas características expressivas expostas na altura, barba, roupa escura, bermuda e bolsa negra não foram associadas ao papel do turista e sim ao forasteiro e possível ameaça, reforçando ainda mais a produção de fotografias mais contextuais sem que houvesse identificação facial e frontal.

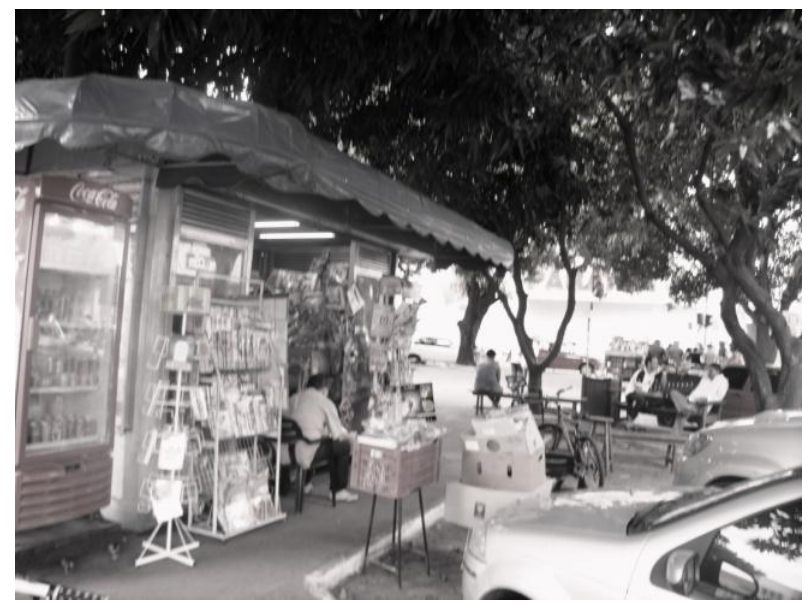

Ilustração 5 - Contexto da banca e aproximação fotográfica. Foto: Marmanillo, 2014.

Pode-se dizer que a passagem do voyerismo para o contato ocorreu de uma forma primeiramente de uma forma frustrada da qual percebi a importância de ter um informante, algum tipo de relação atribuísse as expressões mais aspectos de confiança e mais informações sociais que me tirassem da condição de forasteiro. A importância dessas duas variáveis apresentou-se como fundamental, naquela sociedade cujo medo tem sido um traço historicamente construído. 
Enfim, após as situações embaraçosas, peguei o celular e recorri a um taxista conhecido que trabalhava no posto de taxi da referida Praça, a poucos metros da banca de revista. Esse contato estava associado à existência de uma relação de consumo do serviço de taxi vinculada com o meu próprio papel de morador recente na cidade. Isso porque em meus primeiros dias na cidade peguei o taxi do Sr. Wagner que por minha sorte, trabalha na Praça de Fátima.

Meus trajetos para o supermercado, aeroporto e outros eram sempre solicitados para o mesmo de forma que antes mesmo de pesquisar a Praça de Fátima, esse taxista já poderia ser considerado uma espécie de informante sobre a cidade, já que era comum eu perguntar coisas sobre a cidade e, assim, ir buscando conhecimento do local no qual eu estava recém-chegado. Por meio do Sr. Wagner conheci outro taxista chamado Ademar que trabalha na mesma Praça durante o período noturno.

Nas primeiras interações com o Sr. Ademar ficou claro para mim que essas interações locais funcionam de acordo com sentimentos de medo, confiança e segurança mobilizados de acordo com a quantidade de informações sociais expostas na interação. Para explicar melhor essa relação entre sentimentos e características dos equipamentos expressivos, ou fachada como diria Goffman (2013), posso citar que nas primeiras frases trocadas com o Sr. Ademar foram permeadas de uma desconfiança do mesmo, desconfiança essa que foi cedendo espaço uma confiança, na medida em que eu associava meu conhecimento dele com as informações de seu colega de trabalho, Sr. Wagner e o meu papel de consumidor dos serviços do mesmo.

Após ter percebido a importância dessas informações, passei a me identificar por meio de associações com informações já conhecidas, em uma tentativa constante de reconhecimento. No caso da pesquisa na Praça de Fátima, utilizei-me dessa mesma estratégia, aproveitando-se me do comportamento solicito do Sr. Wagner, realizei uma entrevista ali mesmo na Praça.

Após isso, retornei a banca do Chico apresentando-me como professor e deixando clara essa relação estabelecida com o taxista local. Com um resultado um pouco melhor, o Sr. Francisco Melo Santos (dono da Banca do Chico) disse que poderia dá uma entrevista, mas que deveria ser em outra hora, pois naquele momento estava ocupado. Saindo da banca, lhe disse que tinha lido algo sobre a banca e sua fama. De forma mais entusiasmada ele me respondeu que era conhecida como boca maldita por conta das fofocas. 
Enfim, considerando o estudo de Berreman (1975), autor que defende a necessidade de que sejam explicitadas as condições nas quais as informações foram colhidas, devemos concordar que na primeira interação face a face fui reconhecido como um estranho no local o que me trouxe a preocupação de pensar minha apresentação em relação aos locais, nesse sentido a relação com o taxista constitui um tipo de referência local que me transmitiu maior segurança. Pode-se dizer que a partir de então se iniciou um processo de busca daquilo que Goffman chama de reconhecimento social, ou seja:

O processo de acolher abertamente, ou ao menos aceitar, o início de um engajamento, como quando se devolve uma situação ou sorriso.... o reconhecimento social é uma olhadela que funciona especificamente como um gesto cerimonial de contato com alguém.... Para realizar certas formas de reconhecimento social será necessário que os participantes se reconheçam cognitivamente, ou finjam tê-lo feito, ou se desculpem por não o fazer. (Goffman, 2010: 127).

Nesse sentido, em minha apresentação, para todas as pessoas com que dialoguei ou entrevistei, tentei passar informações que me associasse com representações de morador recém-chegado, consumidor, turista e professor de História e Sociologia interessado em construir uma história da Praça que tivesse como ponto de partida, as experiências das pessoas que viviam cotidianamente na Praça.

Para cada tipo de associação ocorreu um tipo de interação específica: Como turista e estranho foi produzida uma situação de embaraço, como recém-chegado pude obter o contato com um taxista da Praça, como professor interessado em uma história construída a partir dos trabalhadores daquele local obtive uma entrevista com o mesmo, já como professor e conhecido do taxista consegui um melhor contato com o Chico da Banca. Continuando nessa reflexão sobre o processo de interação entre o fotoetnógrafo e os nativos, podemos observar um pouco da experiência de Luiz Eduardo Robinson Achutti que explica a inserção em campo da seguinte forma:

À primeira vista, as pessoas fotografadas tendem a confundir o fotoetnógrafo com o repórter fotográfico. É por isso que antes de começa a trabalhar em campo, o etnógrafo deve, desde os primeiros contatos que estabelece com os membros da comunidade estudada, declarar sua posição de pesquisador que veio fotografá-los e não se apresentar como simples fotógrafo [....]. O etnógrafo deve, portanto retornar a campos repetidas vezes, unicamente para observar, entrar em contato com as pessoas conhecê-las melhor, impregnar-se de seu universo. Como para todo etnógrafo, é extremamente importante que o fotoetnógrafo estabeleça o diálogo desde o início, se faça conhecer, fale de si, daquilo que lhe interessa, do tipo de trabalho que deseja 
realizar. Na fase posterior quando se começar a fotografar, é preciso ter cuidado para não dá a impressão de que se busca impor uma relação de desigualdade e criar um abismo: eu de um lado, vocês de outro; vocês trabalham, vocês vivem; eu fotografo. $\mathrm{O}$ ato de fotografar, na verdade, é apenas uma parte do trabalho que emergirá das relações estabelecidas com as pessoas. (Achutti, 2004: 114).

Descrevendo a relação entre etnógrafo e pesquisados, o trecho valoriza aspectos como a apresentação do pesquisador, a frequência das visitas em campo e a importância do diálogo e aproximação entre pesquisador e pesquisado, tratando-se assim de uma valorização do trabalho de campo. Mais que antagonizar o "eu" e o "outro", o autor explica que o ato fotográfico pode ser pensado como o produto da relação existente entre esses dois "polos". Olhando de outra forma, pode-se dizer que o que está em jogo são os papéis assumidos no processo de interação, e que por mais que exista o desejo de impregnar-se do universo do pesquisado é importante reconhecer que a escolha de tais papéis depende, em grande medida, da situação em que se desenrola o processo de interação, ou seja, não pode ser compreendida como uma escolha a priori, mas decorrente das informações sociais disponíveis nos processos de interação.

\section{Conclusão}

Seja pelo silêncio sobre a socialização das experiências empíricas em campo ou por conta de uma inserção orientada por uma pré-noção que expõe a pesquisa de campo sem percalços ou dificuldades, notamos que a importância de problematizar a relação entre o "eu" e o "outro" - tomando-a enquanto interação, situação e passo fundamental que estrutura todo o processo de coleta de dados. Desse modo, considerar esse aspecto é de extrema importância para pensar as condições da pesquisa etnográfica e explorar uma riqueza de detalhes ocultados quando pesquisador e objeto são tomados, unicamente, como dois polos antagônicos de uma mesma situação.

Tentamos demonstrar que é justamente no processo de interação existente entre o "eu" e o "outro" que ocorrem os imprevistos, surpresas e geralmente é de onde emergem os obstáculos no processo de inserção e coleta de dados. Por meio desse viés é possível problematizar o trabalho acabado e enriquecer as abordagens etnográficas e fotoetnográficas, tomando o ato de pesquisar não pelo resultado, mas sim como aprendizado. 
É possível assim, problematizar o homo academicus (Bourdieu, 2004) em seus habitus de fazer desaparecer os vestígios da pincelada, os toques e os retoques de seus trabalhos. Mais do que um Dom ou habilidade, considerar a pesquisa etnográfica por meio dos aspectos inesperados, experienciados em campo, nos apontou para um aperfeiçoamento da etnografia por meio da valorização de sua dimensão empírica, principalmente, se pensada em termos de cenário, atores e interações.

Enfim, longe de pensar a pesquisa etnográfica por meio de um manual ou abordagem ideológica do campo, compreendemos que as condições de realização de uma pesquisa fotoetnográficas dependem de um conjunto de fatores relacionados às relações sociais e formas de inserções em campo. Tal viés é bastante fértil, tanto no sentido de produzir conhecimento e favorecer o debate em torno dos êxitos ou fracassos obtidos no trabalho de campo, como por apontar a importância de uma reflexão epistêmica sobre o fazer antropológico.

\section{Referências}

ACHUTTI, Luiz Eduardo Robinson. Fotoetnografia da Biblioteca Jardim. Porto Alegre: Editora da UFRGS, Tomo Editorial, 2004.

ACHUTTI, Luiz Eduardo Robinson. Fotoetnografia: A profundidade de campo no trabalho de campo, e outras questões de ordem técnica In: KOURY, Mauro Guilherme Pinheiro (Org.). Sociologia da Imagem: Ensaios Críticos. João Pessoa, GREI, 2004a 155 p. (edição em CDROM).

BERREMAN, Gerald. "Etnografia e Controle de Impressões em uma Aldeia do Himalaia", In: A. Zaluar (Org.). Desvendando Máscaras Sociais. Rio de Janeiro: Francisco Alves, 1975, p. 123-174.

BOURDIEU, Pierre. O Poder Simbólico. Rio de Janeiro: Bertand Brasil, 2004.

CARDOSO DE OLIVEIRA, Roberto. Caminhos da identidade: ensaios sobre etnicidade e multiculturalismo. São Paulo: Edunesp, 2006.

(1976), Identidade, etnia e estrutura social. São Paulo, Pioneira.

DA MATTA, Roberto O ofício de etnólogo ou como ter anthropological blues. In: NUNES, E. de O. A aventura sociológica. Rio de Janeiro: Zahar, 1978, p 23-35.

BOURDIEU, Pierre.Compreender. In: BOURDIEU, Pierre (Org.). A miséria do mundo. Petrópolis: Vozes, 2007, p. 693- 732.

FREGONA, Livaldo. 18 anos de Imperatriz: o que vi, li e ouvi. Imperatriz, MA: Ética, 1998.

FREHSE, F. A Rua no Brasil em questão (etnográfica). Anuário Antropológico, v. 38, p. 99129, 2013. Disponível em:

http://sociologia.fflch.usp.br/sites/sociologia.fflch.usp.br/files/2013\%20-

$\% 20$ Frehse\%20\%28A\%20rua\%20no\%20Brasil\%20em\%20quest\%C3\%A3o\%20-

\%20Artigo\%29_1.pdf

GEERTZ, Clifford. Obras e vidas: o antropólogo como autor. Rio de Janeiro: Editora UFRJ, 2005.

GOFFMAN, Erving. Estigma: Notas sobre a Manipulação da Identidade Deteriorada. 4. ed. Rio de Janeiro: LTC Editora, 1988.

Comportamento em lugares públicos. Petrópolis, RJ: Editora Vozes, 2010. 
2013.

A representação do eu na vida cotidiana. Petrópolis, RJ: Editora Vozes,

LEVI-STRAUSS, Claude. Antropologia Estrutural. Rio de Janeiro: Tempo Brasileiro, 2003.

MALINOWSKI, Bronislaw. Objetivo, método e alcance dessa pesquisa, In: A. Zaluar (Org.). Desvendando Máscaras Sociais. Rio de Janeiro: Francisco Alves, 1975, p. 3976.

MARTINS, C. B. C. Notas sobre o sentimento de embaraço em Erving Goffman. Revista Brasileira de Ciências Sociais (Impresso), v. 1, p. 137-144, 2008.

Recebido em: 24/03/2015

Aprovado em: 13/06/2015 